\title{
LANGUAGE PROJECTION OF STEREOTYPES IN DIFFERENT LINGUISTIC CULTURES
}

\author{
Elleonora V. Maremukova \\ Ministry of Culture of the Kabardino-Balkarian Republic, \\ 360000, Russia, Kabardino-Balkarian Republic, Nalchik, Keshokov street, 43.
}

\begin{abstract}
The article reveals the peculiarities of transmission of stereotypical images of various cultures in the language of a native speaker. Through a comparative study of the material of languages with different structures (English, Russian and Kabardino-Circassian), the specificity of linguistic explication of ethnocultural stereotypes is analyzed. The analysis of language tools demonstrates that stereotype as an integral part of human thought processes and a conceptual picture of the world is inextricably linked with ethnic culture, acting as an accumulator of collective experience and a regulator of individual's behavior, and language not only transmits stereotypes of national thinking and projects the human worldview, but also creates reality, forming corresponding images in the minds of communicants. The study of linguistic material of compared languages made it possible 1) to conclude that language reflects the specific perception of surrounding reality by representatives of different linguistic cultures, due to the national mentality; 2) to identify the peculiarities of national thinking in the process of stereotyping; and 3) to determine the function of stereotypes reflected in language in building a constructive intercultural dialogue. The target audience of the study may include university students following linguistic, ethnocultural programs, employees of educational and research institutions, as well as all interested in a comparative study of languages with different structures.
\end{abstract}

Key Words: language, culture, linguistic culture, worldview, linguistic picture of the world, stereotype, stereotyping

For citation: Maremukova E.V. 2020. Language Projection of Stereotypes in Different Linguistic Cultures. Philological Sciences at MGIMO. Vol. 6. No 4(24). P. 146-155. https://doi.org/10.24833/24102423-2020-4-24-146-155

\section{ЯЗЫКОВАЯ ПРОЕКЦИЯ СТЕРЕОТИПОВ В РАЗНЫХ ЛИНГВОКУЛЬТУРАХ}

\section{Э.В. Маремукова}

Министерство культуры Кабардино-Балкарской Республики, 360000, Россия, Кабардино-Балкарская Республика, г. Нальчик, ул. Кешокова, 43. 
Аннотация. В статье выявлены особенности объективаиии стереотипных представлений различных культур в языке носителя. Посредством сопоставительного изучения материала разноструктурных языков (английского, русского и кабардино-черкесского) проанализирована спеи,ибика лингвистической экспликаиии этнокультурных стереотипов. Проведённый анализ языковых средств демонстрирует, что стереотип как неотьемлемая часть мыслительных процессов человека и кониептуальной картины мира неразрьвно связан с этнической культурой, выступая аккумулятором коллективного опыта и регулятором поведения индивида, а язык не только транслирует стереотипы национального мышления и проецирует человеческое мировидение, но и создаёт реальность, формируя соответствующие образы в сознании коммуникантов. Исследование лингвистического материала сравниваемых языков позволило заключить, что в языке находит отражение специфическое восприятие окружающей действительности представителями разных лингвокультур, обусловленное национальным менталитетом, а также позволило определить особенности работы национального мышления в процессе стереотипизации и изучить функииональную нагрузку стереотиопов, вербализованных в языке, в выстраивании конструктивного межкультурного диалога. Целевая аудитория исследования может включать студентов высших учебных заведений по тингвистическим и этнокультурным программам, работников образовательных и научно-исследовательских учреждений, а также всех заинтересованных в сопоставительном изучении разноструктурных языков.

Ключевые слова: язык, культура, лингвокультура, мировидение, языковая картина мира, стереотип, стереотипизация

Для цитирования: Маремукова Э.В. 2020. Языковая проекция стереотипов в разных лингвокультурах. Филологические науки в МГИМО. Том 6. № 4(24). С. 146-155. https://doi. org/10.24833/2410-2423-2020-4-24-146-155

\section{Введение: актуальность исследования, цели, задачи, методы}

$\mathrm{B}$

условиях глобализации и взаимопроникновения культур и языков особую актуальность приобретает изучение вопросов языкового разнообразия и самобытности этнических культур, содействия их сохранению и развитию. В языкознании укрепляются положения о доминирующей роли родного языка в процессе восприятия человеком мира. Научный лингвистический интерес вызывает трансляция языком культурно маркированной информации его носителей. Актуальность данного исследования заключается в необходимости изучения взаимодействия культуры и языка как разных семиотических систем.

Целью исследования является контрастивное изучение репрезентации в языке национальнокультурных стереотипов на материале трёх разноструктурных языков - английского, русского и кабардино-черкесского. Для достижения поставленной цели предполагается решение следующих задач: определить понятие стереотипа и его характерные особенности; установить различия между процессами стереотипизации и категоризации окружающей действительности; на материале английского, русского и кабардино-черкесского языков изучить специфику восприятия окружающей действительности представителями разных лингвокультур; определить особенности работы национального мышления в процессе стереотипизации; изучить функциональную нагрузку стереотиопов в выстраивании конструктивного межкультурного диалога.

На материале устной разговорной речи, народного фольклора, в том числе паремиологических единиц, а также письменных источников - литературных текстов и словарных изданий - анализируется специфика вербализации этнокультурных стереотипов в рассматриваемых языках. В работе представлен анализ, в первую очередь, ряда этнонимов, представляющих собой «говорящие» названия и заключающих в себе стереотипные качества обозначаемой ими этнической группы, а также идиоматических выражений и отдельных концептов, эксплицирующих этнокультурные ценности и стереотипные представления носителей исследуемых языков. Для анализа эмпирического материала был применён комплекс общенаучных и лингвистических методов, 
в том числе сопоставление, интерпретация, обобщение, методы семантического, структурного и концептуального анализа, выбор которых предопределён спецификой объекта изучения, целью и задачами исследования - изоморфизмом культуры и языка, необходимостью установления их взаимосвязи, выявления особенностей национального ментального устройства посредством анализа языковых знаков и определения механизма объективации этнокультурной информации.

\section{Стереотип, стереотипизация и категоризация}

Теория о взаимозависимости языка и мышления восходит к исследованиям В. Гумбольдта [16]. В продолжение этой темы Э. Сепир и Б.Л. Уорф сформулировали гипотезу языковой относительности $[15 ; 14]$. Э. Сепир полагает, что люди в значительной степени находятся во власти того конкретного языка, который стал средством выражения в данном обществе [15]. В процессе восприятия объектов реальности и их категоризации формируются стереотипы, в том числе стереотипы как по отношению к себе, своей этнической группе в целом, так и к представителям других лингвокультур. Человек окружён стереотипами, диктуемыми его национальной лингвокультурой [8].

В научный обиход термин «стереотип» впервые введён американским социологом и журналистом У. Липпманом, который определил его как схематичное, упрощённое представление о каком-либо фрагменте реальности, предназначенное для восполнения недостающей информации; пометку объектов либо как знакомые, либо как странные и необычные, представляя немного знакомое как очень близкое, а немного непривычное - как абсолютно чужое [4, c. 104].

Стереотип - заранее сформированная человеком мыслительная оценка чего-либо, которая может быть отражена в соответствующем предвзятом поведении. Стереотипы представлены во всех сферах жизни общества в виде различных модификаций.

В научной лингвистической литературе имеет место отождествление стереотипизации и категоризации реальности или рассмотрение стереотипирования как почти неизбежного следствия категоризации окружающей действительности [19]. В концепции П. Шрёдера «стереотип» - это любая форма обобщённого опыта [18, с. 670]. Сторонники данного подхода аргументируют свою точку зрения чрезвычайной сложностью окружающей действительности для человеческого восприятия, в связи с чем люди оперируют её редуцированной моделью. Категоризация подразумевает восприятие конкретной сущности как частного случая более абстрактного явления. Сложность мироустройства и лимитированность человеческого опыта определяют неизбежность процесса категоризации [8]. Новым явлениям необходимо давать имена, включать их в сформированную картину мира, структуру лингвоментального комплекса. Таким образом, слово или имя представляет собой обобщение фрагмента мира определённой этнической культуры в звуковом и графическом обрамлении.

Классическая модель категории Аристотеля предполагает чёткие границы категории, одинаковый статус, эквивалентность всех членов категории [2, с. 22]. Следовательно, если придерживаться позиции приравнивания стереотипизации к категоризации, эта модель наделяет всех объектов подобного процесса эквивалентными характеристиками (например, «россияне» - это категория, которая объединяет всех граждан, зарегистрированных в Российской Федерации). В то время как категория предполагает номинацию (обозначение одним именем группы единиц), стереотипизация - утверждение, формулировка которого требует участия предиката (например, «В России холодно»). При отождествлении стереотипов и категорий возникает вопрос об объективности стереотипов, поскольку категории являются общепринятыми представлениями о том, что определённые частные единицы принадлежат к более крупным, общим абстрактным группам, обоснованность отнесения к которым не вызывает сомнений в обществе. Ситуация со стереотипами другая: доминирует мнение о том, что они являются негативным явлением, поскольку наделяют целый класс объектов или явлений качествами одного объекта или явления, не являющимися неотъемлемыми характеристиками всех членов этих групп, что вводит в заблуждение о наличии или отсутствии этих свойств у отдельных их представителей. Согласно Г. Тэджфелу, стереотипи- 
зация отличается от категоризации: объект можно определить как член определённой категории, не наделяя его стереотипными качествами и допуская его нетипичность и нестереотипность [20].

Человек обобщает существующие представления о предметах или явлениях и даёт им лингвистическое оформление, закрепляя за ними ярлыки-названия, для того, чтобы в следующих упоминаниях в речи использовать их, тем самым облегчая речемыслительную деятельность. Подобное утверждение ослабляет широко распространённую позицию о негативной природе стереотипов, создающих препятствия в процессе межкультурной коммуникации, экспозиционируя их не негативным явлением, предубеждением, предвзятым отношением, а мысленным обобщением наблюдаемых явлений и присвоением им лингвистических ярлыков. Изначально отрицательное отношение к стереотипам является стереотипизацией - предвзятым отношением к роли стереотипов, чему подвержены и учёные, пренебрегающие их нейтральными и позитивными аспектами [10, с. 121]. Исследователями отмечается неоценимая помощь стереотипов в организации информации о мире. Стереотипы часто рассматриваются как упростители и систематизаторы объёмной информации, усваиваемой индивидом в процессе социализации и освоения окружающего мира. Выделяются две важные черты стереотипа, такие как детерминированность культурой и способность экономить усилия и языковые средства [4]. Стереотипы, несмотря на схематизм и обобщённость, подготавливают почву для общения с другими народами и культурами, ослабляя культурный шок [11; 15]. И.С. Кон заявляет, что ни один человек не обладает способностью самостоятельно без участия существующих стереотипов познавать многообразие жизненных событий и явлений окружающей действительности [3, с. 3-5], [8].

\section{Национальные стереотипы}

При изучении роли стереотипов в межкультурном взаимодействии нельзя забывать, что стереотипы всегда национальны [12]. Национальные (этнокультурные) стереотипы делятся на автостереотипы, представляющие собой видение собственного образа и культуры своего народа, и гетеростереотипы, обобщающие взгляды на другие народы и культуры. В концепции Г.У. Солдатовой, автостереотип и гетеростереотип - взаимозависимые единицы, образующие единую целостную личностную и групповую идентичность [9, с. 70], [10, с. 125-12]. Люди осознают свои этнокультурные нормы, общаясь с представителями других культур и проводя с ними параллели $[11$, c. 52]. В подтверждение данного утверждения Н.В. Сорокина приводит идеи А.Г. Здравомыслова о релятивистской теории нации, согласно которой нация раскрывает своё существование прежде всего посредством сопоставления с другими, и то, как её воспринимают другие, является одним из наиболее важных моментов для её собственного мироощущения. Автостереотип усиливается посредством гетеростереотипа - через механизм изолирования от «чужой» группы. Так формируется этноцентризм, определяющий собственную культуру приоритетной, помещающий её в центр и оценивающий другие группы в оппозиции к ней [10, c. 127]. Будучи носителем и в то же время оставаясь заложником языкового и культурного наследия и стереотипов, представитель этнической группы нередко становится неспособным объективно отражать явления, события, другие этносы. На помощь ему приходит стереотип, позволяющий провести разделительную грань между «своими-чужими».

В научной лингвистической литературе преобладает позиция, что автостереотипы преимущественно имеют положительное содержание, то есть собственная этническая группа чаще видится в позитивном свете по сравнению с чужой. Этноцентризм, активно подпитывающий национальные стереотипы, порождает веру в то, что традиционные основы, система убеждений и менталитет материнской культуры являются «единственно правильными, нормальными и приемлемыми» $[7$, с. 13].

Однако следует отметить, что автостереотипы не всегда имеют положительную окраску. В русском языке можно встретить частое употребление выражения «Только русский так может поступить» (с отрицательной коннотацией, к примеру, о неспокойном и свободном на чужой взгляд поведении русских туристов за рубежом, что, возможно, не выходит за рамки дозволенного в 
понимании части представителей самого народа, однако воспринимается как неприемлемое в других культурах, где в приоритете более спокойное поведение и сдержанность), что является автостереотипом негативного содержания. Примеры отрицательного автостереотипа имеются и в английском языке: «Stop being so British and say what you think» - «Перестань быть таким британцем и скажи, что ты думаешь (поделись своим мнением)». Негативный автостереотип, или доминирование отрицательных черт в самооценке этноса, детерминированный иррациональностью поведения представителей определённой части этнического сообщества, следует рассматривать проявлением чувства ответственности за собственную культуру и заинтересованности в её позитивном восприятии другими культурами - положительном гетеростереотипе.

Стереотипы различного эмоционально-оценочного характера могут иметь один и тот же когнитивный компонент, то есть когнитивная составляющая стереотипов может совпадать, а аффективная - отличаться [10, с. 131]. Например, автостереотип американцев - весёлые, раскрепощённые и дружелюбные, в то время как другими этническими группами данные свойства воспринимаются в преломлении собственных культурных особенностей: к примеру, в глазах англичан американцы слишком открытые и шумные (негативный гетеростереотип). Автостереотип англичан - сдержанные и уважающие приватность других людей (позитивный автостереотип), что в свою очередь воспринимается представителями иных культур как проявление собственного превосходства и безразличия к другим (отрицательный гетеростереотип). Несмотря на то, что когнитивный компонент указанных утверждений совпадает, языковые средства выражения этого содержания играют решающую роль в формировании стереотипа, а именно его положительный или отрицательный характер.

Выделяется также контрстереотип - характеристики, приписываемые нетипичным представителям группы, которые, с одной стороны, являясь исключениями из правил, «подтверждают это правило» (достоверность стереотипов) [10, с. 129], с другой стороны - обладают способностью изменить стереотипы [9, с. 71]. Увеличение количества характеристик, отклоняющихся от существующих предубеждений, укрепление позиций контрстереотипов может оказать содействие в изменении сложившихся стереотипов. К индикаторам наибольшей достоверности стереотипа относятся совпадение авто- и гетеростереотипа, длительные контакты между народами, совпадение гетеростереотипов двух этнических групп относительно третьей группы и др. [10].

\section{Языковая экспликация этнокультурных стереотипов}

Одними из наиболее ярких способов лингвистической объективации этностереотипов являются идиоматические выражения. К примеру, в русском языке используется устойчивое выражение «уйти по-английски», что значит «уйти, не попрощавшись». Интерес представляет наличие в английском языке подобного выражения, однако с участием этностереотипа другого народа - французов - «to take a French leave», «to leave in a French way» (уйти по-французски). А во французском языке используется эквивалентная фраза - filer à l'anglaise («уйти, не прощаясь (по-английски»). Предположительно, выражение проникло в русский язык именно через французский язык. Данное обстоятельство может быть интерпретировано таким образом, что представления и стереотипы зарождаются при условии определённой осведомлённости об объекте стереотипизации. Стереотип (или этностереотип) может существовать в обществе о народе или явлении при условии, что члены этого общества имеют представление о нём либо через посредников, либо непосредственно в процессе взаимодействия с ним. При этом неполные знания об иных культурах могут также содействовать появлению национальных этнических стереотипов, основанных на мистических представлениях. В кабардино-черкесском языке имеется поговорка «Зыгуэр щыжаІэм зыгуэр щыщыІэщ» (досл. «там, где что-то говорят, что-то есть», то есть если что-то становится предметом разговора в народе, значит, имеются некоторые основания - не зря ходят слухи). В русском языке, «в каждой шутке - доля правды». Это означает, что стереотипы не возникают на пустом месте, их появление продиктовано определёнными событиями, однако необъективна атрибуция существующих стереотипов ко всем без исключения членам определённой 
группы без учёта индивидуальных характеристик. Приведённый выше пример свидетельствует о заинтересованности русских в англичанах, и указанный стереотип не является негативным, он результат наблюдения русских и передаёт определённые различия в поведении двух народов. Показательно рассмотренное выше наделение друг друга одним и тем же стереотипным свойством у англичан и французов, что вызвано тесной связью культур, многовековой историей, а также традиционным антагонизмом между этими народами.

В рассматриваемом контексте примечательны этнонимы, являющиеся не только результатом категоризации с целью выделения определённой группы людей, объединённых общими признаками (язык, культура, экономика, территория проживания, самосознание, внешний вид, менталитет и другое), но и отражением их наиболее характерных черт в общем для них «говорящем» названии (этнониме).

К примеру, в русском языке этноним «немец» (вместо «German» или «Deutsche») (германец)) восходит к «немати» (говорить непонятно). Праславянское слово «немец» (чужестранец) образовано от «нем» - «немой, неспособный говорить на понятном языке». В более широком смысле данное слово обозначало всех иностранцев, говорящих «непонятно». Кабардино-черкесский язык отражает сходный процесс речемыслительной деятельности по отношению к понятию «иностранец»: каб.-черк. «бзэмыІу» («иноязычный») [1] (иностранец, чужестранец, букв. «немой» - примечание автора): «зи бзэр мыІу» - «тот, язык которого не звучит», то есть не звучит понятно, разборчиво, что приводит к непониманию его окружающими. Данная параллель обнаруживает сходные лингвокультурные характеристики процесса языковой фиксации «лица, находящегося на территории государства, гражданином или подданным которого он не является» в русском и кабардино-черкесском языках. В то же время термин «заморский», «overseas» (где акцент делается на территориальное разграничение, в данном случае водными ресурсами) в русском и английском языках выступает одним из примеров языковых универсалий. В кабардино-черкесском языке имеется термин «псым адрыщІкІэ» (за морем/рекой (букв. «за водой»)) со значением «на другой территории», «далеко», однако он не закреплён в языке для обозначения лиц, проживающих на этой территории (в фольклорных текстах встречается выражение «псым адрыщІкІэ щыпсэухэр» («живущие за рекой, водой»), а в современном литературном кабардино-черкесском языке зафиксировано выражение «хамэ къэрал цЈыху («иностранец, чужестранец»).

B английском языке появление этнонима «Irish» (ирландцы, ирландский) детерминировано стереотипным представлением об этой этнической группе (англ. «ire» («anger») [13] - гнев, злость, ярость), историческими предпосылками формирования которого считаются вспышки народного гнева в форме стихийных бунтов против многовековой социально-экономической и этноконфессиональной политики Соединённого королевства по отношению к ирландцам.

Идиоматические выражения и отдельные концепты, функционирующие в активном словаре носителей языка, выступают транслятором этнокультурной информации, декодирование которой выполняет решающую роль в установлении эффективного межкультурного диалога. К примеру, в разговорном английском языке используется выражение “Are you kidding (me)?!", восходящее к "to kid" ("to say something as a joke, often making someone believe something that is not true”) [13] (сказать что-то в шутку, заставляя кого-либо поверить во что-либо, не являющееся правдой), "make a kid of someone" (букв. «относиться к кому-либо, как к ребёнку, не воспринимать его серьёзно, считать его наивным и воспользоваться этой детской наивностью»): "Are you making a kid of me?” («Ты шутишь?», «Ты издеваешься?», «Ты серьёзно?!» (досл., «Почему ты относишься ко мне, как к ребёнку, выставляешь меня дураком?»). Происхождение данного выражения можно также соотнести с поведением субъекта в предложении “Не is just kidding” («Он всего лишь шутит» (ведёт себя несерьёзно, как ребёнок). “То kid someone” - «дразнить кого-либо» (как это обычно делают дети), “to kid yourself” - «позволять себе верить чему-либо, желая, чтобы это было правдой» (наивно верить, как дети). Полным эквивалентом выражения “Are you kidding?!” в русском и кабардино-черкесском языках является «Ты шутишь?!» («УгушыІэу ара?»), в то время как использование стереотипа ребёнка в подобном контексте, как это имеет место в английской лингвокультуре, наблюдается реже. Такие паремиологические единицы, как «Устами младенца 
глаголет истина» в русском языке, «Джэд нэхърэ джэдыкІэ нэхъ Іущщ» («Яйцо мудрее курицы»), «Жьым щытхъуи, щІэр къащтэ» («Похвали старшего, выбери молодого»), «Нэхъыжьым жьэ ет, нэхъыщІэм гъуэгу ет» («Дай старшему слово, молодому - дорогу») в кабардино-черкесском языке выступают подтверждением того, что в русской и кабардино-черкесской лингвокультурах ребёнок чаще ассоциируется не с неполноценностью, наивностью или несерьёзностью, а с источником правды, справедливости, новых идей и перспективных решений.

В английском языке, в частности в американской разговорной версии, употребляется выражение "You dog!” («Ты собака!», «Да ты собака!») в адрес лица, добившегося каких-либо успехов, пройдя через определённые приключения (в данном случае стереотип собаки обусловлен одной из её характеристик - стремлением гоняться за своей целью и достигать её). В русском языке в подобном контексте чаще используется выражение «Ты тигр!», в кабардино-черкесском языке «Ар аслъэнщ» («Он лев», ср. в англ. “You are a lion”), обусловленное такими стереотипными признаками этих диких животных, как «быстрота», «ловкость», «ярость», «сила» и др. Интересно отметить редкость использования выражения «Ты лев» в кабардино-черкесском языке в качестве обращения ко второму лицу, что можно объяснить лингвокультурной особенностью адыгов не хвалить представителей своего народа как обращаясь к нему непосредственно, так и в его присутствии, чтобы он не возгордился и не остановился на достигнутом и продолжал стремиться к большему. В кабардино-черкесском языке, несмотря на любовь адыгов к собакам, сравнение с ними имеет преимущественно негативную коннотацию, что возвышает человека над всеми живыми существами: «Ар хьэщ», «Ар хьэм хуэдэщ» («Он собака», «Он подобен собаке»- он жестокий, способен на многие злодеяния). В данном случае происходит лингвокультурное маркирование таких стереотипных черт собак, как «злость», «бешенство», «агрессивность».

Лингвокультурный интерес представляет лексема «подкидыш» в русском языке, имеющая коннотацию «ребёнок, подкинутый матерью чужим людям» [6] (вследствие нежелания его содержать и воспитывать - прим. автора). Эквивалентом данного термина в английском языке является «foundling» ("a young child who is left by parents and then found and cared for by someone else”) [13] (младенец, оставленный родителями и затем найденный и принятый другими людьми на воспитание, букв. найдёныш - примечание автора). Интересно отметить, что в русском языке в данном случае лингвистически объективируется культурно осуждаемый факт подкидывания ребёнка, в английской лингвокультуре - поощряемый факт нахождения и, соответственно, спасения оставленного (подкинутого) ребёнка (подкинули, однако нашли, спасли), а в кабардиночеркесском языке - отсутствие лингвистического обозначения подобного культурного концепта является показателем неприемлемости в адыгском обществе подкидывать и оставлять ребёнка на произвол судьбы.

Примечательна репрезентация концепта «лошадь/конь» в русской лингвокультуре при характеристике трудолюбивого, выносливого человека («пашет, как лошадь», «лошадиное здоровье»). Стереотипные признаки лошади восходят к истории и быту русского народа («запрягать тройку лошадей», «перевозить на лошадях груз»). В английском языке лошадь исторически символизировала власть и знатность, а её образ является одним из неотъемлемых компонентов «английскости»: "When you are on a great horse, you have the best seat you will ever have" - Sir Winston Churchill («Когда Вы на отличной лошади, у Вас лучшее место, которое у Вас когда-либо будет» - Сэр Уинстон Черчилль) [17, с. 37]; “A horse! a horse! My kingdom for a horse!" (W. Shakespeare «Richard III), 1594) (Коня! Коня! Моё королевство за коня!) (перевод авторский). Выражением подобного отношения к лошадям являются проводимые и в сегодняшнее время скачки Royal Ascot, любительницей которых является и сама королева Елизавета II. В этом плане кабардино-черкесская лингвокультура обнаруживает сходство с английской: стереотип лошади детерминирован почтительным и трепетным отношением адыгов к лошадям. В качестве тягловой силы адыги применяли крупный рогатый скот. Кабардинская порода лошадей славится издавна, в том числе за рубежом. Кабардинские князья и богатые дворяне имели крупные конские заводы. В языке используются афоризмы «Адыгэм и ныбэ егъэныкъуэри, и шым и ныбэ ирегъэкъу» («Адыг оставляет себя голодным и кормит своего коня»), «Дунейм щынэхъ дахэр сыт? Адыгэ хъыджэбзырщ. 
Абы нэхъ дахэжыр сыт? Адыгэшу къабзэрщ. Адыгэшыр зыгъэдахэр сыт? АдыгэлІ губзыгъэрщ. Ар зыгъэгубзыгъэр сыт? И бзэрщ - адыгэбзэрщ» («Что на свете красивее всего? Адыгская девушка. Что красивее её? Адыгская лошадь. Что делает красивой адыгскую лошадь? Умный адыг. Что делает его умным? Его язык - адыгский язык»). Кони наравне с людьми являются действующими лицами Нартского эпоса адыгов. Народный фольклор возносит коней так же, как и героев, которым они принадлежат. «Нарт эпосым лІыри шыри зэхуегъадэ, лІым кІэрилъхьэр шыми кІэрелъэхьэ» (Нартский эпос приравнивает коня к герою, наделяет его теми же качествами, которыми обладает герой) $[5$, с. 9].

\section{Заключение}

Проведённый анализ позволяет заключить, что культура, мировоззрение, жизненные установки и приоритеты народа отражаются в выборе языковых средств для обозначения предметов и явлений окружающей действительности.

Язык выступает в качестве средства экспликации стереотипных представлений этнической общности, неотъемлемым компонентом культуры и наряду с этим является его инструментом, позволяя аккумулировать и транслировать коллективный опыт, отражает культуру, условия жизни, самосознание народа и его менталитет, национальный характер и систему ценностей.

Стереотип неразрывно связан с этнической культурой и является неотъемлемой частью концептуальной картины мира. Этнический стереотип транслирует культурно детерминированную информацию о предметах и явлениях мира.

Использование стереотипа происходит автоматически, даже если он противоречит эмпирической картине мира. Расхождение между стереотипом и эмпирическим опытом связано с тем, что в сознании человека присутствует не реальное отражение действительности, а его образ.

Стереотипы полагаются одним из препятствий на пути успешного построения диалога культур. Любое утверждение, выступая обобщением имеющегося опыта, категоризацией или стереотипизацией, не является абсолютно достоверным, неизменным и зависит от перспективы рассмотрения. Преодоление сложившихся стереотипов требует определённой работы - изучения и языкового оформления объекта познания. В этом и особенность стереотипов - в их относительной устойчивости и проблематичности разрушения.

При этом стереотипы выполняют ассистивную функцию в познавательном процессе, а также построении межкультурного диалога, обеспечивая субъекта познания готовыми категориальными представлениями, существующими упрощёнными базовыми элементами окружающего мира. Проверка их достоверности, укоренение или разрушение с появлением новых последуют после интеграции в языковую и культурную среду. Лингвокультурная интеграция способствуют переосмыслению сложившихся предрассудков и негативных стереотипов, приближает к их преодолению и упрощает процесс межкультурного взаимодействия. Таким образом, необходимо помнить о дуализме стереотипов, которые могут как искажать действительность, так и симплифицировать процесс усвоения информации.

По отношению к стереотипам более оправданным можно считать такой подход, который предполагает выводы и обобщения, основанные на собственном опыте, учёт конструктивных функций стереотипов, построение параллелей и целенаправленное маркирование универсальных категориальных характеристик объектов познания в целях устранения существующих негативных установок, формирования новых и, следовательно, обеспечения бесконфликтного и эффективного межкультурного общения.

(C) Маремукова Э.В., 2020 


\section{Список литературы}

1. Апажэ М.Л., КІуэкІуэ Ж.Н. Адыгэ-урыс псалъалъэ. Псалъэ 27 000-м нэблагъэ итщ. Филологие щІэныгъэхэмкІэ доктор БищІо Б.Ч. и редакцэкІэ. Налшык: «Эльбрус», 2008. Н. 704. [Апажев М.Л., Коков Дж.Н. Кабардино-черкесско-русский словарь. Около 27000 слов / Под научной ред. доктора филологических наук Б.Ч. Бижоева. Нальчик: «Эльбрус», 2008. 704 c.]

2. Вилинбахова Е.Л. Материалы к курсу лекций «Лингвистическое изучение стереотипов»: учебно-методическое пособие. СПб.: СПбГУ, 2015. 72 с.

3. Кон И.С. Психология предрассудка (о социально-психологических корнях этнических предубеждений) / И.С. Кон // Новый мир. 1966. № 9. С. 188-204.

4. Липпман У. Общественное мнение / пер. с англ. Т.В. Барчуновой; ред. перевода К.А. Левинсон, К.В. Петренко. М.: Институт Фонда «Общественное мнение», 2004. 384 с.

5. Нартхэр. Къэбэрдей эпос. ЕтІуанэ къыдэкІыгъуэ. Ред. БжэныкІэ М.М. Тхылъ тедзапІэ центр «Эльфа»: Налшык, 1995. Н. 559. [Нарты. Кабардинский эпос. На кабардинском языке. Ред. М.М. Бжеников. Нальчик: Издательский центр «ЭльФа» Республиканского полиграфического комбината им. Революции 1905 г., 1995].

6. Ожегов С.И. Словарь русского языка: Ок. 57000 слов / Под ред. докт. филол. наук, проф. Н.Ю. Шведовой. 14-е изд., стереотип. М.: Рус. яз., 1982. 816 с.

7. Романов А.С. Этнические стереотипы армейской субкультурной среды США в знаках языка и культуры. М.: Типография военного университета, 2017. 231 с.

8. Семашко Т.Ф. Стереотип как фрагмент языковой картины мира // Филологические науки. Вопросы теории и практики. Тамбов: Грамота, 2014. № 2 (32): в 2-х ч. Ч. II. С. 176-179.

9. Солдатова Г.У. Психология межэтнической напряженности / Г.У. Солдатова. М.: Смысл, 1998. 389 с.

10. Сорокина Н.В. Методическая типология стереотипов как компонент содержания обучения иностранным языкам в ВУЗе // Н.В. Сорокина. Язык и культура, 2013. № 3 (23). С. 120-139.

11. Тер-Минасова С.Г. Язык и межкультурная коммуникация. М.: СЛOBO/SLOVO, 2000. 624 c.

12. Чеканова С.А.. Роль стереотипов в межкультурном общении // Современная наука: актуальные проблемы теории и практики. Серия Гуманитарные науки: Научно-практический журнал. М.: Научные технологии, 2017. Выпуск №12. C. 263-265.

13. Cambridge Dictionary. Cambridge University Press, 2020. URL: https://dictionary.cambridge.org/ (accessed 29 April 2020).

14. Carroll J.B., Chase S. Language, Thought, and Reality: Selected Writings of Benjamin Lee Whorf. MIT Press, 1964.278 p. URL: https://books.google.ru/books?id=W2d1Q4el00QC\&dq=Whorf+B.L.+Science+and+Linguistics.\&hl=ru\&source=gbs_ navlinks_s (accessed 29 April 2020).

15. Goodman Mandelbaum D. (ed.). Selected Writings of Edward Sapir in Language, Culture and Personality. University of California Press, 1949.617 p. URL: https://books.google.ru/books?id=NG6VQqGfP2cC\&dq=Sapir+E.+Selected+Writings+of+Edward+Sa pir+in+Language,+Culture+and+Personality\&hl=ru\&source=gbs_navlinks_s (accessed 29 April 2020).

16. Humboldt W.F. Uber die Verschiedenheit desmenschlichen Sprachbaues und ihren Einfluss auf die geistige Entwickelung des Menschengeschlechts. Berlin, 1836. 511S. Digitized: 4 June 2013. URL: https://books.google.ru/books?id=BKpWAAAAcAAJ\&p rintsec=frontcover\&hl=ru\#v=onepage\&q\&f=false (accessed 29 April 2020).

17. Price S. 1001 Best Things Ever Said About Horses, Rowman \& Littlefield, 2006. 400 p.

18. Schröder P. Sprachliches Funktionieren und interaktive Funktion von Stereotypen in einer Güteverhandlung vor dem Schiedsmann / P. Schröder // Das Güteverfahren vor dem Schiedsmann. Soziologische und kommunikationswissenschaftliche Untersuchungen. Köln, 1987. S. 667-722.

19. Stephan, W.G., \& Stephan, C.W. Intergroup relations / W.G. Stephan, C.W. Stephan. Boulder, CO: Westview Press, 1996.240 p.

20. Tajfel H. Human groups and social categories: Studies in social psychology / Tajfel H. Cambridge: Cambridge University Press, $1981.369 \mathrm{p}$.

\section{References}

1. Apazhev, M.L., Kokov Dzh.N. Kabardino-cherkessko-russkii slovar. Okolo 27000 slov [Kabardino-Circassian-Russian dictionary]/ Pod nauchnoi red. doktora filologicheskikh nauk B. Ch. Bizhoeva. Nal'chik: «El'brus», 2008. 704 s.

2. Vilinbakhova, E.L. Materialy k kursu lektsii «Lingvisticheskoe izuchenie stereotipov»: uchebno-metodicheskoe posobie [Materials for the lecture course «Linguistic study of stereotypes»: a teaching tool]. SPb.: SPbGU, 2015. $72 \mathrm{~s}$.

3. Kon, I.S. Psikhologiia predrassudka (o sotsial'no-psikhologicheskikh korniakh etnicheskikh predubezhdenii) [Psychology of prejudice (on the socio-psychological roots of ethnic prejudices)] / I.S. Kon // Novyi mir. [New world]. 1966. № 9. S. 188-204.

4. Lippman, U. Obshchestvennoe mnenie [Public opinion] / per. s angl. T.V. Barchunovoi; red. perevoda K.A. Levinson, K.V. Petrenko. M.: Institut Fonda «Obshchestvennoe mnenie», 2004. 384 s.

5. Narty. Kabardinskii epos. Na kabardinskom iazyke. [Nart Saga. Kabardian Epos. In Kabardian]. Red. M.M. Bzhenikov. Nalchik: Izdatel'skii tsentr «El'fa» Respublikanskogo poligraficheskogo kombinata im. Revoliutsii 1905 g., 1995.

6. Ozhegov, S.I. Slovar' russkogo iazyka. Ok. 57000 slov [Ozhegov S.I. Dictionary of the Russian language: approx. 57,000 words] / Pod red. dokt. filol. nauk, prof. N. Shvedovoi. - 14 izd., stereotip. M.: Rus. iaz., 1982. 816 s.

7. Romanov, A.S. Etnicheskie stereotipy armeiskoi subkul'turnoi sredy SShA v znakakh iazyka i kul'tury [Ethnic stereotypes of the US army subcultural environment in signs of language and culture]. M.: Tipografiia voennogo universiteta, 2017. $231 \mathrm{s.}$ 
8. Semashko, T.F. Stereotip kak fragment iazykovoi kartiny mira [Stereotype as a fragment of the linguistic picture of the world] // Filologicheskie nauki. Voprosy teorii i praktiki [Stereotype as a fragment of the linguistic picture of the world]. Tambov: Gramota, 2014. № 2 (32): v 2-kh ch. Ch. II. C. 176-179.

9. Soldatova, G.U. Psikhologiia mezhetnicheskoi napriazhennosti [Psychology of interethnic tension] / G.U. Soldatova. M.: Smysl, 1998. $389 \mathrm{~s}$

10. Sorokina, N.V. Metodicheskaia tipologiia stereotipov kak komponent soderzhaniia obucheniia inostrannym iazykam $\mathrm{v}$ VUZe [Methodological typology of stereotypes as a component of the content of teaching foreign languages at a university] / N.V. Sorokina // Iazyk i kul'tura [Language and Culture], 2013. № 3 (23). S. 120-139.

11. Ter-Minasova, S.G. Iazyk i mezhkul'turnaia kommunikatsiia [Language and Intercultural Communication]. M.: SLOVO, 2000. $624 \mathrm{~s}$.

12. Chekanova, S.A. Rol' stereotipov v mezhkul'turnom obshchenii [The role of stereotypes in intercultural communication] // Sovremennaya nauka: aktual'nye problemy teorii i praktiki. Seriia Gumanitarnye nauki: Nauchno-prakticheskii zhurnal [Modern science: actual problems of theory and practice. Humanities series: scientific and practical journal]. M.: Nauchnye tekhnologii, 2017. Vypusk №12. S. 263-265.

13. Cambridge Dictionary. Cambridge University Press, 2020, dictionary.cambridge.org/ (accessed 29 April 2020).

14. Carroll, J.B., Chase S. Language, Thought, and Reality: Selected Writings of Benjamin Lee Whorf. MIT Press, 1964.278 p., books.google.ru/books?id=W2d1Q4el00QC\&dq=Whorf+B.L.+Science+and+Linguistics.\&hl=ru\&source=gbs_navlinks_s (accessed 29 April 2020).

15. Goodman, Mandelbaum D. (ed.). Selected Writings of Edward Sapir in Language, Culture and Personality. University of California Press, 1949. 617 p., books.google.ru/books?id=NG6VQqGfP2cC\&dq=Sapir+E.+Selected+Writings+of+Edward+Sapir+in+Language,+Culture+and+Personality\&hl=ru\&source=gbs_navlinks_s (accessed 29 April 2020).

16. Humboldt, W.F. Uber die Verschiedenheit desmenschlichen Sprachbaues und ihren Einfluss auf die geistige Entwickelung des Menschengeschlechts. Berlin, 1836. 511S. Digitized: 4 June 2013, books.google.ru/books?id=BKpWAAAAcAAJ\&printsec=frontcover\&hl $=\mathrm{ru} \# \mathrm{v}=$ onepage\&q\&f$=$ false (accessed 29 April 2020).

17. Price, S. 1001 Best Things Ever Said About Horses, Rowman \& Littlefield, 2006. 400 p.

18. Schröder, P. Sprachliches Funktionieren und interaktive Funktion von Stereotypen in einer Güteverhandlung vor dem Schiedsmann // Das Güteverfahren vor dem Schiedsmann. Soziologische und kommunikationswissenschaftliche Untersuchungen. Köln, 1987. S. 667-722.

19. Stephan, W.G. Intergroup relations / W.G. Stephan, C.W. Stephan. Boulder, CO: Westview Press, 1996. 240 p.

20. Tajfel H. Human groups and social categories: Studies in social psychology / Tajfel H. Cambridge: Cambridge University Press, $1981.369 \mathrm{p}$

\section{Сведения об авторе:}

Маремукова Эллеонора Владимировна - кандидат филологических наук, главный специалист-эксперт Министерства культуры Кабардино-Балкарской Республики (Россия, Кабардино-Балкарская Республика, г. Нальчик). Сфера научных и профессиональных интересов: лингвокультурология, сопоставительное языкознание, теория языка.

E-mail: elleonora16@mail.ru

Конфликт интересов: Автор заявляет об отсутствии конфликта интересов.

\section{About the author:}

Elleonora V. Maremukova - PhD, chief specialist-expert of the Ministry of Culture of the Kabardino-Balkarian Republic (Russia, Kabardino-Balkarian Republic, Nalchik). Sphere of scientific and professional interests: cultural linguistics, comparative linguistics, language theory.

E-mail: elleonora16@mail.ru

Conflicts of interest: The author declares absence of conflicts of interest. 